\title{
Quality Control Management of Traditional Jasmine Rice Production and Processing Methods
}

\author{
Shiwen Lin ${ }^{1}$, Songkoon Chantachon ${ }^{1} \&$ Sastra Laoakka ${ }^{1}$ \\ ${ }^{1}$ The Faculty of Cultural Science, Mahasarakham University, Khamriang Sub-District, Kantarawichai District, \\ Maha Sarakham Province, Thailand \\ Correspondence: Shiwen Lin, The Faculty of Cultural Science, Mahasarakham University, Khamriang \\ Sub-District, Kantarawichai District, Maha Sarakham Province 44150, Thailand. E-mail: \\ shiwenlin135@gmail.com
}

Received: June 3, 2014 Accepted: July 17, 2014 Online Published: September 22, 2014

doi:10.5539/ach.v7n1p75 URL: http://dx.doi.org/10.5539/ach.v7n1p75

\begin{abstract}
The Tung Kula Rong Hai jasmine rice industry suffers from low economic efficiency and low employment standards, which weaken the economies of local communities. This qualitative research was conducted in the areas of Surin, Roi-Et and Sisaket Provinces in North-eastern Thailand using the research tools of basic survey, observation, interview and focus group discussion. Results found that changes to traditional rice cultivation caused the quality of rice to diminish. The quality control management of jasmine rice production still has problems and the rice processing lacks identity and standards. Given these factors, the added value of rice products is at a low level. In order to solve these problems, the jasmine rice industry of Tung Kula Rong Hai must manage its quality control procedures more systematically and thoroughly on the principles of traditional knowledge.
\end{abstract}

Keywords: Tung Kula Rong Hai, jasmine rice, quality control, processing, traditional agriculture

\section{Introduction}

The agricultural sector is important for Thai society and generates many benefits, which include the creation of employment opportunities, production of food, reduction of poverty and defence against global warming. Production is linked to the local culture and lifestyle, which are based on traditional relationships with the surrounding environment. Even though the agricultural sector benefits from the natural resources at its disposal, production must be boosted with foreign imports. This raises production costs, reduces agricultural tendencies, limits the value of goods processed by general industries and hinders progress. The development of agricultural goods in order to increase profit and sale, standardise, campaign against the use of chemicals and promote of contractual agriculture will enable businesses to compete while having no effect on natural resources. Sponsorship for research and development of production and processing and development and strengthening of agricultural processing industries based on traditional knowledge and creative invention are needed to raise the level of product value, create standardized quality of produce and make Thai products more appealing to the domestic and international markets (Office of the National Economic and Social Development Board, 2011).

Rice is the most important agricultural product in Thailand and aromatic rice is the biggest group, in both non-glutinous and glutinous forms. Aromatic rice is different from other varieties because of the distinctive fragrance that remains from the paddy to the plate. For the most part, the aromatic rice plant is tall, resistant to sunlight and responsive to fertilizer. Each plant has a unique aroma, which arises from the different conditions in its planting. Two parts of the same rice plant that are grown in different areas will smell differently (Pontanee, 1990). Rice with a fragrant aroma is popular in Asia and is gaining popularity in Europe and America thanks to its smell and texture (Weerapet, 1988). The aromatic rice sold most throughout the world is Basmati, which is grown on both sides of the Indus River in Pakistan and India. Another country famous for exporting aromatic rice is the United States of America, which sells both Della Aromatic and Pecan Rice (Singh, Singh \& Khush, 2000). Rice has been grown in Thailand for over 5,000 years. The rice varieties that are supported by the Thai government and planted across the country are KDML105 (non-glutinous), RD15 (non-glutinous), Nahng Mon-S4 (non-glutinous) and RD6 (glutinous). However, the aromatic rice grown most in Thailand and exported throughout the world is Kao Horm Mali 105 (KDML105). This white variety is soft, particularly aromatic and 
with low amylase levels. Important markets for the Thai economy are United States of America, the European Union, China, Hong Kong, Singapore and Malaysia, who all pay high prices (Pontanee, 1990).

The origin of Jasmine rice was in Bang Khla District, Chachoengsao Province, which is an area of saline, sandy soil with no flooding. Nowadays, this has been transformed into an industrial and residential area and the most famous and largest area of rice production in present-day Thailand is at the Tung Kula Rong Hai area of the North-eastern Region (Isan). The dryness of the Tung Kula Rong Hai had become a symbol of the Isan region and local stories told of how locals were forced to migrate from the area to find more hospitable terrain. However, these stories decreased thirty years ago in 1982 when the Australian government was recruited to help adapt the soil conditions. This was achieved by flattening the soil and adding fertilizer. Rice plants were then planted, both glutinous and non-glutinous. It was revealed that Jasmine rice had a more fragrant aroma and higher quality than other varieties. When the Thai Rice Department supported the cultivation of Jasmine rice in the Tung Kula area, the previously discarded territory was developed and became the largest production area of Jasmine rice (Reutidet, 2006). Although, Jasmine rice yield is not exceptionally high, the Tung Kula area is large enough to ensure that producers can generate a high income. For the most part, the rice is exported abroad and is renowned as Tung Kula Rong Hai Jasmine Rice (Suwandee, 2003).

For the reasons given, the Department of Intellectual Property allocated a geographical indicator (GI) to the Tung Kula Rong Hai area in 2006. The European Union also bestowed a GI on the area in March 2013. This was the first GI recognition for an ASEAN country and the third recognition for a country outside of Europe by the European Union. This is a significant step in promoting the name, raising the level and increasing the value of Jasmine rice from the Tung Kula Rong Hai area, thus increasing the ability for Thailand to compete in the global economy. Additionally, this helps support the income of people in the five provinces covered by the Tung Kula Rong Hai area, which are Surin, Mahasarakham, Roi-Et, Yasotorn, and Sisaket. However, the Tung Kula Rong Hai area is faced with problems. Soil deterioration, lessening rice quality and aroma, lack of internationally standardized management and production, low product value and poor general agriculture mean that the Tung Kula Rong Hai area is still a developing area. It is necessary to research the quality control management of Jasmine rice and its processing to address these problems using the principles of traditional knowledge and benefit the community economy of Tung Kula Rong Hai.

\section{Objectives}

The research had three objectives:

1) To study the changes of traditional rice farming methods and problems in the Tung Kula Rong Hai area;

2) To study current conditions and problems with quality control management and processing of Jasmine rice in the Tung Kula Rong Hai area;

3) To study a model for quality control management and processing of Jasmine rice based on traditional knowledge principles in the Tung Kula Rong Hai area.

\section{Methodology}

This qualitative research, aimed at the objectives, was conducted by document research and field study, using survey, participant and non-participant observation, structured and non-structured interview and focus group discussion (Chantachon, 2010). Data was validated using data triangulation and methodological triangulation. Data was then categorized in correspondence with the research aims and analyzed. The research period was from June 2012 to May 2013.

The research area was chosen using a purposive sampling method according to the objectives of the investigation. The area covered Surin, Roi-Et and Sisaket Provinces. The research population was composed of fifteen key informants, seventy casual informants and twenty general informants. The key informants were five government administration officials, five jasmine rice business owners and executives and five sub-district chiefs and village leaders. The casual informants were ten government production officials, fifty workers from Jasmine rice industries and ten local experts in agriculture and traditional knowledge. The general informants were ten reception level workers at jasmine rice businesses, five traders and five general farmers.

\section{Results}

\subsection{Changes to Rice Farming Methods and Problems in the Tung Kula Rong Hai Area}

Before the introduction of jasmine rice to the Tung Kula Rong Hai area, the objective of rice cultivation was for consumption in the household. Farmers mostly grew indigenous glutinous rice and a small amount of non-glutinous varieties, which were both highly unsusceptible to disease. Families would grow many varieties of 
rice, meaning that they needed harvesting at different times. This caused a lack of urgency in the farming process. Water was only sourced from natural rainfall. Tools used in rice cultivation were homemade and used human and animal power. Fertilizers were naturally produced from cow and buffalo waste and no chemical fertilizers were used. There were many steps in the cultivation process, responsibilities were shared among family members and there was a high level of cooperation among community members, who would help one another to harvest and process the rice. As the entire process relied on nature, respect was customarily paid to the relevant spirits at each stage. Rice was meticulously managed at the farming level. Pure, organic rice was produced naturally and continuously.

After the introduction of jasmine rice to the Tung Kula Rong Hai area, the rice farming methods dramatically changed. Nowadays, ninety percent of the land is used to farm Kao HormMali 105. However, the local people prefer to eat glutinous rice and only grow the jasmine rice for sale. This has made the jasmine rice an important economic plant for the local area. The varieties of rice that were once grown here have disappeared in response to high external market demand. The Tung Kula Rong Hai area has almost entirely been developed for the cultivation of jasmine rice and each family plants large quantities, harvests at the same time and works rapidly until they have no more energy. As the reasons for production shifted from internal consumption to external sale, so machinery was increasingly used. Chemical fertilizers are now in the majority, as are chemical herbicides and pesticides. Mechanical ploughs enable ploughing to be completed in a day; combine harvesters enable harvesting to be completed in a day (Figure 1 and Figure 2). Farming has become faster and easier, so farmers have become 'farm managers'. With this change, more and more people have been allowed to go to the cities to work, leaving the farms to be maintained by the elderly and children. This means that the farms are not always meticulously cared for. The changes have also seen the shift from free communal help at harvest time to employed communal help. The beliefs and ceremonies have also disappeared, the soil quality has deteriorated, the surrounding environment and ecology has been harmed, the rice quality has reduced, especially the aroma. With the need for speed, it has become increasingly difficult for the industry to manage the rice.

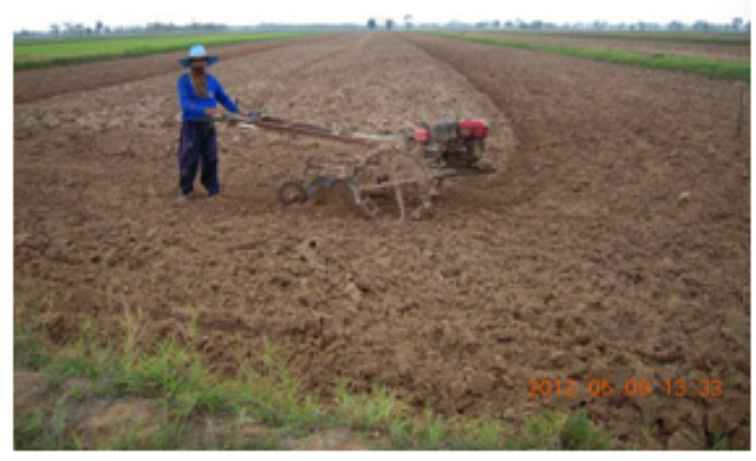

Figure 1.A mechanized plough

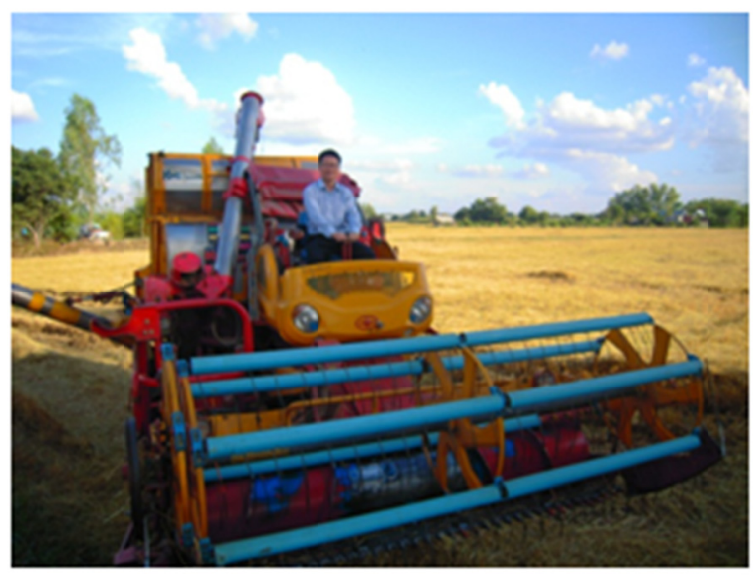

Figure 2. Modern harvesting machinery 


\subsection{Current Conditions and Problems with Quality Control Management of Jasmine Rice and Processing in Tung Kula Rong Hai}

\subsubsection{Current Conditions and Problems with Quality Control Management of Jasmine Rice}

\subsubsection{Current Conditions}

Organic jasmine rice businesses recognize and control the quality of rice before agreeing to buy it, especially with regards residue because they contract and control workers to use organic methods in each stage of production. This includes soil testing and quality control checks of planting. The factors and stages of planting are systematically recorded and chemical products are banned from the cultivation process. Social cooperatives that deal in jasmine rice also recognize and maintain quality of rice prior to purchase. At the same time there are training courses and support for agricultural production according to the system of good agricultural practices (GAP), which now has over 2000 members. Private rice mills have little or no practices of quality control in the cultivation process.

The government program to purchase rice from farmers is aimed at private rice mills and community businesses. Private rice mills, especially large sized mills and middle-men, do not separate their materials by location, which is not appropriate for the GI rating of jasmine rice from Tung Kula Rong Hai. At the same time, community businesses that deal in both general and organic jasmine rice purchase rice from specific locations, such as KongtunkaoSurin Organic Agricultural Cooperative. Burlap sacks for containing jasmine rice can be used twice. When the sacks are filled, the details of the rice must be recorded on the sack, including the name of the farmer, the location, the farmer's code, day, month, year, bag number and either ACT (Organic Agriculture Certification Thailand) or BCS to control the quality of the rice (Figure $3 \&$ Figure 4). As the government program to purchase rice from farmers set a higher price than the market, it is able to drive the market. Nowadays, the majority of rice grown in the Tung Kula Rong Hai area is sold through the government program and private businesses or middle-men choosing to purchase outside of the program are only able to buy very small quantities of rice.

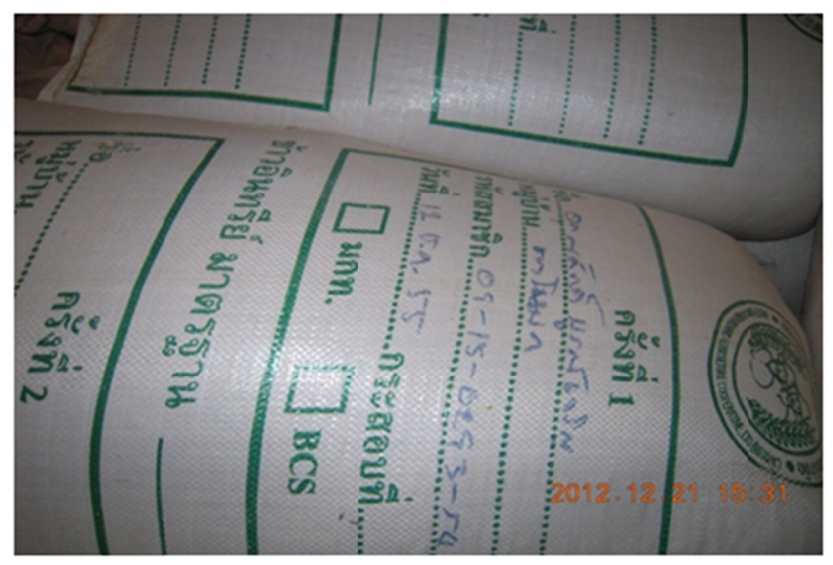

Figure 3.Rice sacks used by KongtunkaoSurin Organic Agricultural Cooperative

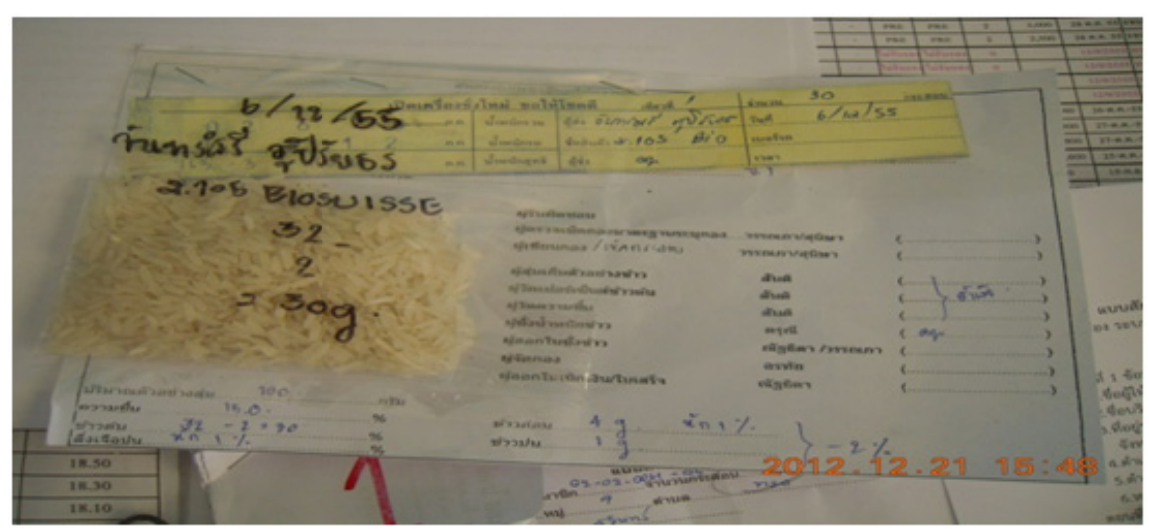

Figure 4. Recorded information of rice crop by KongtunkaoSurin Organic Agricultural Cooperative 


\section{1) Examination of rice}

The program of rice examination in businesses is the same in each province. Examination consists of moisture level measurement, separation of foreign objects, testing for mixed rice plants and yield examination (as a percentage). These tests are purely on the physical aspects of the rice and there are no tests for residue or aroma. The tests are related to the direct purchase value and the mills will separate the rice into grades for ease of sale. For the most part, businesses studied during this research used similar testing techniques by using the eyes to look, the hands to feel and tools to assist. There is heavy reliance upon experience and traditional knowledge of the testers. This is particularly the case for the Surin Organic Agricultural Cooperative and Sunkaochumchon Community Corporation Group, Ban Umsaeng, who do not use any tools in the testing process. The Rasipanit Sri Saket Rice Mill (2004) use dyes to test their rice.

2) Recording Rice quality

Community businesses that process organic jasmine rice record details of the rice from the farm to the sale and keep samples of the harvested product. The rice bags are also kept and the records are clear and thorough. This means that the rice can be conveniently and accurately traced back to the farmer who planted it. For cooperatives that process general jasmine rice, quantities and important quality details are recorded.

3) Reducing moisture in rice

Reducing moisture in rice is an important issue for quality control management of jasmine rice. There are two methods of reduction that are used nowadays, which are sun-drying and machine-drying. Sun-drying is a traditional method carried out by spreading the rice in a courtyard (Figure 5). This procedure relies on the weather and there is no way of controlling the temperature or the moisture levels. If it rains, the rice could be ruined and there is a high chance of contamination. The advantage of sun-drying is the minimal cost incurred. Machine-drying enables the processors to effectively control the temperatures and the moisture levels. Rice that has been machine-dried is standardized and the yield is high. There is also minimal chance of contamination. The major disadvantage is the high operating cost because, for the most part, farms in the Tung Kula Rong Hai area have only one harvest and the machine dryers are therefore used just once a year. The manager of the Rasipanit Sri Saket Rice Mill (2004) (personal communication, 2013) explained that 'the ovens are only used for two months at most each year. This makes the investment in a machine dryer worthless.' In general, private rice mills use machine dryers to reduce moisture, while more traditional community businesses adopt sunning methods.

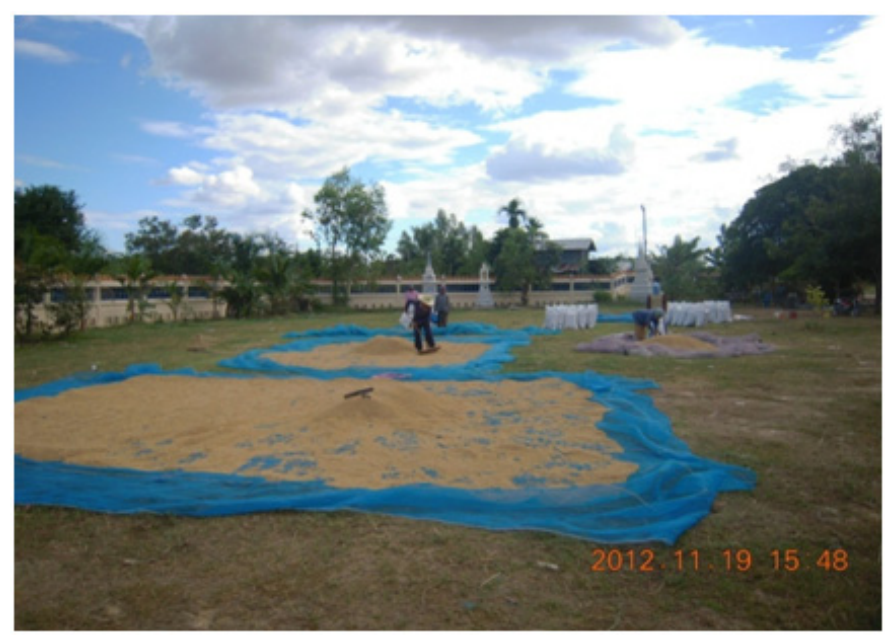

Figure 5. Sun-drying of rice in a courtyard

\section{4) Maintenance of un-milled rice}

The storage of un-milled rice is another important step of quality control in the processing of jasmine rice. There are many ways to store the rice, such as in a barn, in a silo or in a storehouse. Each method has positives and negatives. In a barn, there is good ventilation and the rice can be stored for a long time. However, the storage efficiency is low and it requires a lot of manpower. In a silo, the temperature and moisture levels can be controlled but they are expensive and can overheat and ruin the rice. In a storehouse, other tools or methods can 
be used to help, such as sacks. Additionally, storage is orderly and allows for ventilation, while the rice can be placed on plastic or in boxes to protect against moisture and fans can be used to control the temperature. The companies will mostly prefer the storage methods that they are familiar with and have used before.

\subsubsection{Problems}

There are five problems with current quality control management:

- Because there are no agricultural business contracts, the general rice mills cannot conduct quality control before they purchase the rice.

- As the quality control testing is only done at the time of purchase, only physical tests may be conducted and chemical tests cannot be used.

- Few agriculturalists farm organically or according to GAP, which means that the majority of rice is not separated from that which comes from outside the Tung Kula Rong Hai area and its quality data is not easily traced. This is not appropriate for the geographic indicator of Tung Kula Rong Hai jasmine rice.

- As there is no planning for the timing of rice planting and rice harvests, the rice of each household is not at the same level of ripeness when gathered. Rice that is overripe will be brittle and processing yield will be low. Rice that is not yet ripe enough will become withered when the moisture is removed.

- Due to global warming, the climate is changing so that rains occasionally occur during the harvest season. This means that the processing mills are unable to fully reduce the excess moisture in the rice, which will become rancid and yellow.

\subsubsection{Current Conditions and Problems with Jasmine Rice Processing}

\subsubsection{Current Conditions}

Workers in each of the rice mills studied during this investigation were highly experienced. For the most part, they had learned their trade from their parents. The majority of private companies were family businesses that had passed their traditional knowledge through the generations. Even though they may now use modernized equipment, their procedures have never been internationally standardized. The large rice mills and cooperatives used modern international equipment and had brand-named tools, such as Satake and Buhler. Community businesses preferred domestic brand products.

The larger mills have more steps to rice processing than the smaller businesses, allowing for finer processing. The steps of large mills include cleaning,hulling the rice,separation of brown rice from husks,removal of grit (Figure 6),removal of rice bran, whitening, separation of weeds and broken milled rice,polishing,removal of the rice plant from the milled and polished rice and rice colour sorting. Ordinarily there are two stages of polishing but these are flexible. At the Rasipanit Sri Saket Rice Mill (2004) there are three whitening and three polishing steps; at Fai Surin Rice Mill, there are three whitening stages and two polishing stages; at the KasetwisaiAgricultural Cooperative Rice Mill, the rice is whitened twice and polished twice but this can be increased to three times and the whole process adapted to include extra cleaning of the milled rice, an additional grit removal stage, an additional stage for separation of weeds and broken milled rice, two additional stages for removal of the rice plant from the milled and polished rice and an additional stage for rice colour sorting. This thorough process will produce the highest grade of rice. For middle and small level community businesses, there will be fewer steps and less manpower required. In general, there will be no stage for polishing the rice, removal of grit or colour separation. However, some mills, such as Surin Organic Agricultural Cooperative have installed colour sorting machines (Figure 7). The middle and smaller sized mills do have access to high quality rice that can be controlled. The quality of the rice is also recorded from the location of the cultivation to the individual farmer, and this information is passed on to the customer. The larger mills will only produce general jasmine rice of both first and second grade, while the middle and smaller mills will process organic rice. These mills mostly produce second grade organic white and brown rice, although Sunkaochumchon Community Corporation Group, Ban Umsaeng produces organic brown germinated rice and organic rice flour. 


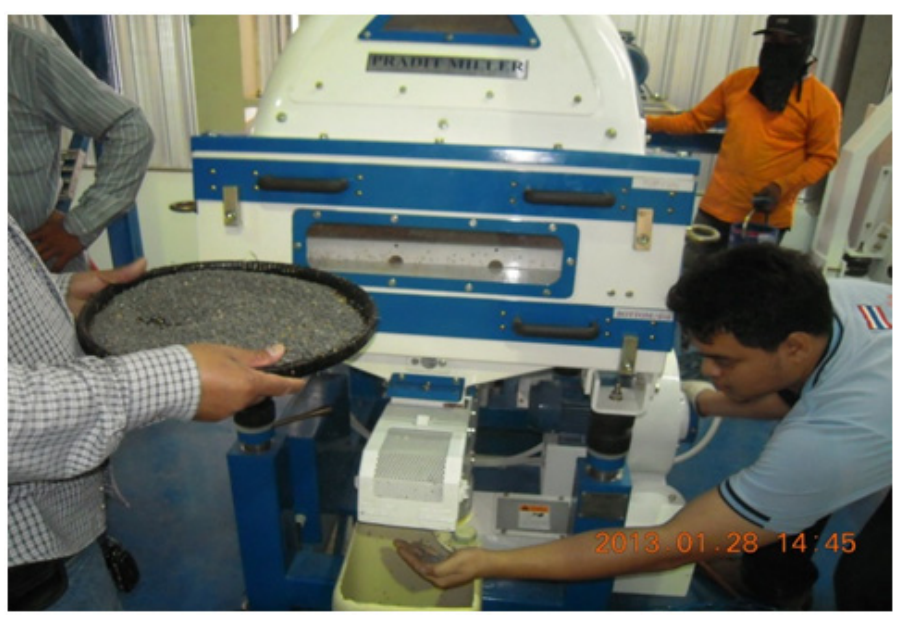

Figure 6. A machine for removing grit from the rice

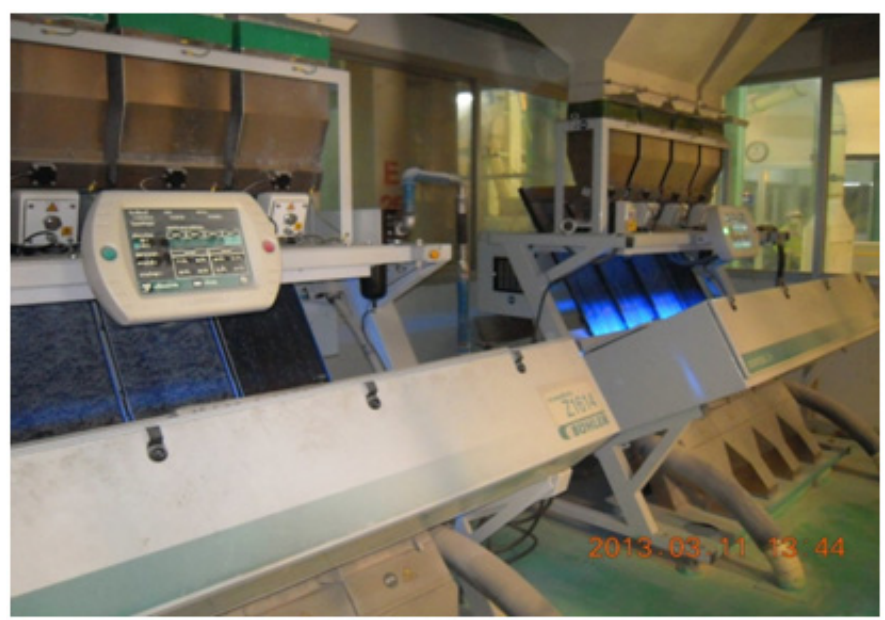

Figure 7.Rasipanit Sri Saket Rice Mill (2004)colour sorting machine

\subsubsection{Problems}

- Middle and smaller sized mills do not have complete tool sets, especially machinery for removing grit from the rice and colour sorters. This makes the rice dangerous and also means that black and yellow rice is able to pass through the system.

- As the rice is mostly sold to central traders operating out of Bangkok and to protect the budget, the rice does not meet the standards of ISO, GMP and HACCP. There is also no intention to produce rice that falls into line with the designated GI.

- There is a lack of final product variety, especially in larger mills that mainly produce milled rice. This results in a low value and low grade of rice. The mills have little power over price-setting and there is high competition, which often results in the lowering of prices. The mills operate at only about $5 \%$ profit, which means that they try to increase the business efficiency and reduce the rice processing costs.

4.3 A Model for Quality Control Management of Jasmine Rice and Its Processing for the Community Economy of Tung Kula Rong Hai

In order to solve the current problems and raise the level of jasmine rice business so that the community economy of Tung Kula Rong Hai will be stronger, it is necessary to create a model to manage the quality control of jasmine rice and its processing in Tung Kula Rong Hai based on traditional agricultural principles and incorporating modern developments. 


\subsubsection{Quality Control Management from Root to Harvest by Contractual Agriculture}

Holding villages or sub-districts as agencies is to be achieved by forming contracts with community household farmers and maintaining a GAP model of rice cultivation (for private mills and large community cooperatives) and organic farming (for middle-sized and smaller businesses) according to GI standards for jasmine rice of TungKula Rong Hai, which requires detailed and thorough data that can be evaluated and traced back. There must also be control of factors and behaviours in the rice cultivation. Community businesses, especially those trading in organic jasmine rice, must establish contracts with farmers. This will clearly define the rights, benefits and roles of all parties. Techniques and experiences should be recommended to farmers, who should also receive assistance in sourcing organic plants and fertilizers. There must be thorough examination and quality control management of soil and cultivation practices and these should also be recorded and easily traced back. Aside from receiving income from the sale of their rice, the farmers should also be rewarded in bonuses from the community businesses. The farmers should overlap occupations as workers in the processing mills, so to reduce the problems of seasonal inactivity, increase individual income and alter the local infrastructure. A number of the local businesses are encouraging the farmers to plant organic vegetables such as Sunkaochumchon Community Corporation Group, Ban Umsaeng, who support the growth of organic soy beans after the rice season. This is a way of improving the quality of soil for the jasmine rice in the next season. Contract farming is an effective method for the cultivation of jasmine rice according to GAP and organic agricultural principles and will strengthen the community economy of the Tung Kula Rong Hai area.

\subsubsection{Planning for Rice Cultivation, Harvesting and Reduction of Moisture by the Method of Machine-drying}

It is necessary for private and community mills to plan rice cultivation and harvesting with farmers who have plots of land adjacent to one another. The local community or village is responsible for harvesting the rice in time, according to the ripeness of the plant. Given the increased likelihood of unseasonal rains ruining the rice crop, the processing mills should create or move to a purpose-built drying store to increase the yield of the rice crop. This is an important stage of processing that will increase the value and quality of the rice.

\subsubsection{Focus on the Completion of All Stages of Rice Processing}

In general, the machinery of the large rice mills in the Tung Kula Rong Hai area is at a good level and there are appropriate steps to ensure that rice is of a high standard. There is also good protection against grit and metal. For middle and smaller-sized mills, it is necessary for them to invest in machinery to remove grit from the rice and sort rice colours. The traditional method of yard-drying used in the community businesses leads to an increased risk of grit in the rice, which could affect the safety of the final jasmine rice product. A colour sorter would help remove the black, yellow and glutinous rice from the final batch, which would increase the standard of the rice.

\subsubsection{Emphasis on Management according to International Standards and the Geographical Indicator (GI)}

It is necessary for cultivation and processing to be carried out according to international standards in order to create confidence in the safety and cleanliness of the product. For this to be achieved, production must follow good manufacturing practice (GMP) and employ a system of hazard analysis and critical control points (HACCP). Additionally, general mills should register and conduct business in line with the GI of Tung Kula Rong Hai to increase the value of their product.

\subsubsection{Emphasis on Product Variety to Increase Product Value and Employment Opportunities}

Jasmine rice can be processed to create a variety of products and almost nothing of the original plant needs to be wasted. Germinated brown rice contains amino acids, vitamins and metallic elements that can help the nervous system, digestive system, stress levels and sleep patterns. Germinated brown rice is twice as expensive as milled jasmine rice. The shoots sell for 80 baht per kilogram while the milled rice sells for 40 baht per kilogram. The price reflects the increased number of steps required for germinated brown rice processing. The development of this side of the industry is a way to increase employment. Aside from this, rice bran oil is also very expensive at 1000 baht per kilogram. 100 kilograms of rice bran can produce six kilograms of oil. The high vitamin content makes the oil suitable for cosmetics. The development of these extra products will increase the value of rice cultivation, increase employment and benefit the local economy of Tung Kula Rong Hai.

\section{Conclusion}

Geographical and natural assets allow Tung Kula Rong Hai to produce the highest quality jasmine rice in Thailand, which is the predominant source of income for the area. To develop the community economy, it is necessary to raise the level of product value and employment so that rice processing standards match the quality of the rice. This will help create further employment opportunities. Quality control management of jasmine rice 
must be conducted from the first stages of planting and thorough details of quality control data must be traceable back to every stage of cultivation and processing. This makes it increasingly necessary to adopt principles of contract farming, GAP and organic agriculture. All procedures must be in accordance with the geographical indicator of Tung Kula Rong Hai jasmine rice. With regards rice processing, all processing steps must be followed and product variety must be increased. The processing of jasmine rice must be in accordance with international standards and the GI. If this model is implemented, the traditional knowledge of the Tung Kula Rong Hai jasmine rice industry will have a higher value, strengthen the local economy and enable the products to compete domestically and abroad.

\section{References}

Chantachon, S. (2010). Advanced qualitative research procedure [in Thai]. Mahasarakham: Mahasarakham University Press.

Office of the National Economic and Social Development Board. (2011). The eleventh national economic and social development plan [in Thai]. Bangkok: Office of the Prime Minister.

Pontanee, A. (1990). Economic aromatic rice plants that should be developed [in Thai].Kaenkaset, 18(2).

Reutidet, P. (2006). Adaptation of farming communities in Tung Kula Rong Hai [in Thai]. Mahasarakham: Mahasarakham University Press.

Singh, P. K., Singh, U. S., \& Khush, G. S. (2000).Aromatic rice. New York, NY: Science Publisher.

Suwandee, P. (2003). Aromatic rice of Tung Kula in the Tung Kula culture of 'khem, haeng, laeng, sai', Tung Kula 'salt kingdom' 2500 years from the first age to the wealthy age of aromatic rice [in Thai]. Bangkok: Matichon.

Weerapet, P. (1988). Knowledge of rice [in Thai]. Bangkok: Thai Wattanapanit.

\section{Copyrights}

Copyright for this article is retained by the author(s), with first publication rights granted to the journal.

This is an open-access article distributed under the terms and conditions of the Creative Commons Attribution license (http://creativecommons.org/licenses/by/3.0/). 